Revista aSEPHallus de Orientação Lacaniana

Núcleo Sephora de Pesquisa sobre o Moderno e o Contemporâneo

ISSN 1809 - $709 \mathrm{X}$

\title{
Considerações acerca da noção de imagem em psicanálise
}

\author{
Matheus Henrique Kunst \\ Psicólogo pela Universidade Estadual da Paraíba / UEPB \\ Mestrando do Programa de Pós-graduação em Teoria Psicanalítica pela Universidade Federal do Rio de \\ Janeiro / UFRJ \\ E-mail: matheuskunst@hotmail.com
}

Resumo: Este trabalho realiza uma abordagem introdutória à noção de imagem em psicanálise. Inicia-se com uma reflexão acerca do estatuto do imaginário na estrutura dos novos sintomas. Em seguida, articula duas proposições de Jacques-Alain Miller sobre as imagens em psicanálise com uma revisão de textos fundamentais dos Escritos de Jacques Lacan. Conclui refletindo sobre a elaboração do conceito de objeto a no ensino de Lacan e sua correlação com a arte moderna.

Palavras-chave: Imagem; novos sintomas; objeto $a$; arte moderna; psicanálise lacaniana.

\section{Considerations on the notion of image in psychoanalysis}

This work performs an introductory approach to the concept of image in psychoanalysis. It begins with a reflection on the status of the imaginary order in the structure of the new symptoms. Then, it articulates two propositions of Jacques-Alain Miller about the images in the psychoanalytic theory with a review of some of the fundamental writings in Jacques Lacan's Écrits. It concludes b reflecting on the development of the concept of object $a$ in the teaching of Lacan and its correlation with modern art.

Key-words: Image; new symptoms; object $a$; modern art; Lacan oriented psychoanalysis.

\section{Considérations sur la notion de l'image dans la psychanalyse}

Ce travail réalise une introduction sur le concept d'image dans la psychanalyse. Il débute par une réflexion au sujet du statut de l'ordre imaginaire dans la structure des nouveaux symptomes. Ensuite il articule deux propositions de Jacques-Alain Miller sur les images dans la psychanalyse avec une révision de textes fondamentaux des Écrits de Jacques Lacan. En conclusion une réflexion sur le développement du concept d'objet a dans l'enseignement de Lacan et sa correlation avec l'art moderne.

Mots-clés: Image; nouveaux symptoms; objet $a$; art modern; psychanalyse lacanienne. 


\section{Considerações acerca da noção de imagem em psicanálise}

Matheus Henrique Kunst

Neste artigo, pretendo inicialmente promover uma reflexão acerca da relação entre a dimensão imaginária e a clínica dos novos sintomas e, posteriormente, apresentar dois desenvolvimentos teóricos realizados por Jacques-Alain Miller acerca do estatuto da imagem que se encontram em "A imagem rainha" (Miller, 1997) e em "La imagem del cuerpo en psicoanalísis" (Miller, 2006). No primeiro texto, Miller elenca as três imagens que sobrevivem à deflação imaginária que resulta de uma análise, quais sejam, o corpo próprio, o corpo do Outro e o falo. No segundo, ele formula um matema que reúne as multiplicidades de considerações de Lacan a respeito da imagem, matema que também orienta uma clínica calcada no diagnóstico diferencial e que considera a apreensão da imagem na estrutura. Articulo e fundamento, então, esses desenvolvimentos com uma revisão concisa dos Escritos (Lacan, 1998) - principalmente a partir dos textos "O estádio do espelho como formador da função do eu", de 1949, e "Subversão do sujeito e dialética do desejo no inconsciente freudiano", de 1960 - no que tange a acepção da imagem para Jacques Lacan. Finalizo comentando acerca da deflação imaginária na psicanálise e na arte moderna.

Na extensão do ensino de Jacques Lacan, o imaginário é conhecido como um registro da experiência que faz tríade com o real e o simbólico. A noção de imagem adquire o estatuto de elemento do imaginário somente na condição de ser tomada como um significante. Essa é a prerrogativa proposta por Jacques-Alain Miller em "A imagem rainha" (Miller, 1997), compilação de uma conferência no Rio de Janeiro, na ocasião do V Encontro Brasileiro do Campo Freudiano, em 1995.

Considerar a imagem como elemento próprio a uma concepção do imaginário, que não se desvencilha da proeminência do simbólico, é um desenvolvimento que está nitidamente presente no âmbito do início do ensinamento de Lacan e das apresentações das conferências registradas nos Escritos. A constatação de que uma matriz simbólica comparece no cerne daquele que será o primeiro paradigma do imaginário, qual seja, o estádio do espelho e a apreensão do corpo próprio na imagem especular, está presente no escrito de 1949. É a partir dos desdobramentos simbólicos de uma subjetivação que a imagem do corpo próprio, categoria de imagem que Lacan privilegia ao conceber a especificidade da função da experiência imaginária na espécie humana, adquire sua premência.

Realizar novamente uma apreensão da noção de imagem em psicanálise é poder, também, ter a oportunidade de colocar os próprios fundamentos teóricos em revisão com a clínica e a contemporaneidade.

\section{Novos sintomas e a questão imaginária}


A questão da imagem e do imaginário está re-situada na própria compreensão teórica e clínica acerca dos novos sintomas. Com falta de garantia da eficácia reguladora da função paterna, a noção de sintoma sofre uma torção ao ponto de não ser tomada unicamente como uma formação de compromisso, noção clássica de sintoma em psicanálise, proposto por Freud. Segundo Tania Coelho dos Santos, no tocante à estrutura neurótica, "os novos sintomas não têm, em princípio, a estrutura do sintoma clássico, como um retorno do recalcado". Esses sintomas se apresentam e são compreendidos "como soluções que reparam os efeitos da castração, como se tratasse de um defeito na constituição narcísica" (Zucchi \& Coelho dos Santos, 2007, p. 63). Trata-se de soluções que não se configuram como respostas - respostas sintomáticas - ao cabo do inconsciente e do conflito neurótico clássico entre o desejo e o eu. Esse desvencilhamento com o saber inconsciente, que inicialmente dificulta o sujeito atribuir uma suposição de saber ao analista, reabre obstáculos de desconhecimento próprios à via imaginária, facilitando que essas soluções proporcionem a impregnação dos sujeitos em identificações imaginárias - bulímicos, toxicômanos, anoréxicos, consumistas compulsivos, eternos depressivos, viciados em sexo, etc.

Segundo Coelho dos Santos, "essas novas identificações, em que prevalece o imaginário, requerem que o analista eleve o fenômeno à dignidade de estrutura" (Zucchi \& Coelho dos Santos, 2007, p. 65). O aspecto compulsivo dessas soluções, sintomas prêt-à-porter, revela que o empuxo ao gozo do objeto da pulsão que elas vinculam condiz com um prevalecimento da via imaginária, ou seja, com uma permanência e insistência das relações de objeto no âmbito do narcisismo, como tentativas de lidar com a falta instaurada pela subtração de gozo na castração. A "subida do objeto $a$ ao zênite social" (Lacan, 1992) e a "redução da autoridade do saber do mestre à legalidade do diploma universitário" (Lacan, 2008) são condições sociais intimamente relacionadas à promoção dessa sintomatologia atual, condições que indicam a entrada da psicanálise e a expansão do capitalismo no mundo.

A noção de solução é "trans-estrutural" (Zucchi \& Coelho dos Santos, 2007) e as identificações que nela se vinculam consistem em "defesas frente ao real como impossível de suportar" (Furman, 2014). Segundo Jacques-Alain Miller, "no plano da identificação, não há certeza, (...) nada mais faz do que encobrir essa falta que está no núcleo do ser" (Miller, 2009, p. 168). Desse modo, se as soluções são defesas, cabe à clínica psicanalítica na contemporaneidade "centrar-se na desmontagem da defesa, desordenar a defesa contra o real" (Miller, 2014).

Em suma, se identificações imaginárias se vinculam às soluções frente ao real sem ordem, aos novos sintomas, temos uma clínica que vem lidando cada vez mais com uma certa manipulação do lugar da imagem na estrutura, de modo a não desvincular da experiência psicanalítica a dimensão do corpo. Estamos, portanto, na perspectiva clínica do último ensino de Lacan que considera o imaginário um dos elos entre o simbólico e o real. 


\section{Um matema para as imagens}

Nos detenhamos, a partir daqui, em um aprofundamento da importância teórica e clínica da noção de imagem e de identificação imaginária.

Tomar a imagem como encobridora de uma falta é o ponto de partida de Jacques-Alain Miller (2006, p. 382) ao formular um matema que, segundo ele, resume as múltiplas de considerações de Jacques Lacan a respeito da imagem:

$$
\mathrm{i}(\mathrm{a}) / \mathrm{a} /(-\varphi)
$$

Esse matema, também apresentado em Silet - Os paradoxos da pulsão de Freud a Lacan (Miller, 2005), pode ser lido da seguinte forma: imagem do corpo próprio, e abaixo, o objeto pequeno $a$ sobre menos phi da castração imaginária. No primeiro momento da formulação do matema, temos a incidência da imagem sobre a um déficit orgânico; no segundo, o menos primário, relativo ao déficit orgânico, é o próprio efeito da castração e a entrada da diferença sexual que o corpo do Outro implica; no terceiro, a carga libidinal, o objeto $a$. É possível observar que nessa formulação também se deduz as três imagens que "sobrevivem ao naufrágio do mundo da imagem na psicanálise", "as imagens rainhas" (Miller, 1995, p. 578), quais sejam, a corpo próprio apreendido na imagem especular, o corpo do Outro que se vela e o falo que se apresenta na forma erigida do pênis que se transforma em significante organizador da libido.

O olhar, segundo Miller (1995, p. 580), não é uma imagem rainha. Ele está fora da captação da imagem especular. É algo a mais, mais-de-gozar, posto em segredo pela castração. É um além do estádio do espelho (Miller, 1995, p. 585) que Lacan pode formular quando desembaraça o escópico do especular a partir da noção de objeto $a$, objeto no qual se vincula a libido que escapa à imagem fálica e à imagem especular do corpo próprio, mas que pode, mediante o fantasma, ser condensado pelo sujeito em partes do corpo do Outro.

Compreendemos que o matema da imagem $[i(a)$ / a / (- $\varphi)]$, proposto por Miller, é uma formulação vinda do campo matêmico-conceitual, de uma ideia de como a imagem subsiste na estrutura; assim como a fórmula da fantasia - do fantasma - é um "índice de uma significação absoluta" (Lacan, 1998, p. 830) referente ao desejo.

Propomos, para prosseguir, remetermo-nos aos Escritos de Jacques Lacan para encontrar mais subsídios para a compreensão de como as imagens se perfilam no âmbito estrutural.

\section{A imagem especular, o organismo e a função da consciência}

É a partir de "O estádio do espelho como formador da função do eu", de 1949, que Lacan fundamenta uma tese, então inédita no interior da psicanálise, relativa à importância da imagem na constituição subjetiva e na concepção psicanalítica de narcisismo. A imagem especular, a imagem 
refletida no espelho, torna-se o principal paradigma ao se tratar do imaginário. Desta forma, a noção de narcisismo elaborada por Freud ganha um novo âmbito teórico ao ser sinalizado na constatação de uma experiência psíquica que se deduza observação da criança em seus primeiros meses. A imagem especular tem efeitos formadores, "como uma identificação", diz Lacan, e o que ele denomina de estádio do espelho, é uma "transformação produzida no sujeito quando ele assume uma imagem" (Lacan, 1998, p. 97). Essa assunção que ocorre nas primeiras relações do sujeito com o outro formata o próprio processo que será reconhecido no âmbito do estruturalismo lacaniano como o eixo imaginário.

O que é evidente nesse escrito é o destaque que Lacan dá ao lugar do organismo humano e à sua condição: prematuro no nascimento e em descontinuidade e discordância à natureza. É a incidência da imagem, portanto, e seus os efeitos formadores, efeitos gestálticos que, no organismo caótico e fragmentado, constitui-se a imago corporal e ergue-se "a permanência mental do [eu]" (Lacan, 1998, p.98) que estarão retroativamente em oposição à experiência de fragmentação corporal.

A condição de descontinuidade e a discordância do organismo são fundamentais na medida em que, diferente de outros animais, a relação do humano com a natureza, diz Lacan, é alterada. Ao humano não cabe simplesmente uma imagem que funcione para estabelecer a relação do organismo com o mundo natural, relação entre Innerwelte Umwelt - terminologia adotada pela fenomenologia advinda do biólogo estoniano Jakob Von Uexküll - afinal, para além desse tipo de imagem, o sujeito privilegia a imagem do corpo próprio. Lacan poderá concluir posteriormente essa questão, ao considerar que a psicanálise implica "o real do corpo e o imaginário de seu esquema mental" (Lacan, 1998, p. 818).

Lacan também inicia em "O estádio do espelho" um importante debate acerca da função da consciência. Contrapõe-se ao existencialismo - empreitada na época a cabo de Jean-Paul Sartre com a sua tentativa de fundamentar uma psicanálise existencial -, criticando toda acepção da função da consciência que não se baseia no efeito alienante da imagem e na ilusão de autonomia provida dos "desconhecimentos constitutivos do eu" (Lacan, 1998, p. 102). Quinze anos depois, Lacan retomará essa questão, em "Posição do inconsciente no Congresso de Bonneval", dizendo que "a única função homogênea da consciência está na captura imaginária do eu por seu reflexo especular no espelho e na função de desconhecimento que Ihe permanece ligada" (Lacan, 1998, p. 846).

Temos, portanto, a partir do desenvolvimento inicial da noção de imaginário em Lacan, os subsídios que articula o primeiro momento da formulação do matema proposto por Miller. A incidência do reconhecimento da imagem do outro especular, como imagem do corpo próprio, sobre o déficit que se localiza no âmago do organismo.

\section{A imagem fixa e o significante. Eu ideal e ideal de eu}


A proeminência do imaginário é de grande importância nos primeiros anos do ensinamento de Lacan, ao ponto de considerar que "é sempre em volta da sombra errante de seu próprio eu que estruturarão todos os objetos do seu mundo. Eles terão um caráter fundamentalmente antropomórfico, digamos mesmo egomórfico" (Lacan, 1978, p. 198). Por outro lado, é importante considerar que desde "O estádio do espelho", Lacan já considera que, concomitante à assunção da imagem, perfila-se a própria matriz simbólica da qual advirá toda a dialética ulterior - a identificação imaginária se efetua por uma marca simbólica.

A assunção jubilatória de sua imagem especular por esse ser ainda mergulhado na impotência motora e na dependência da amamentação que é o filhote do homem nesse estágio de infans parecer-nos-á, pois, manifestar, numa situação exemplar, a matriz simbólica em que o [eu] se precipita numa forma primordial, antes de se objetivar numa dialética da identificação com o outro e antes que a linguagem the restitua, no universal, sua função de sujeito. (Lacan, 1998, p. 97)

Lacan também considera que afixação em uma imagem especular e o júbilo do infans estão relacionados à anuência da imagem pelo outro, momento basal que, em um primeiro período teórico, relaciona-se com a própria possibilidade do sujeito de se identificar com a imagem do seu semelhante, dando-lhe condições para que passe do o eu especular ao eu social (Lacan, 1998, p. 101).

Constata-se a partir da leitura dos Escritos que o estatuto dessa passagem, que vincula o eu às situações socialmente elaboradas, tem seus pormenores. É a consistência teórica do próprio modo como Lacan considera o que Freud desenvolveu em "Introdução ao narcisismo" (Freud, 2010), de modo a poder encontrar seu lugar teórico na sua concepção de inconsciente estrutural. No texto célebre sobre a noção de narcisismo, Freud, além de considerar os tipos de escolhas de objeto tema que aprofundará em "Pulsão e seus destinos" (Freud, 2010) -, lança mão das noções de ideal de eue eu ideal. Lacan poderá, então, localizá-los de forma mais precisa, atendendo a sua concepção de inconsciente estrutural e desenvolvendo o que ele chama de matriz simbólica no cerne do imaginário, quando explora detalhadamente a diacronia própria ao grafo do desejo, em "Subversão do sujeito e dialética do desejo no inconsciente freudiano", de 1960.

Passemos então a explorar esse escrito.

No bosquejo dos labirintos do grafo do desejo e atento à lógica da retroação, Lacan deixa registrado, no primeiro andar do grafo, "o processo imaginário que da imagem especular vai até a constituição do eu, no caminho da subjetivação pelo significante" (Lacan, 1998, p. 824): 


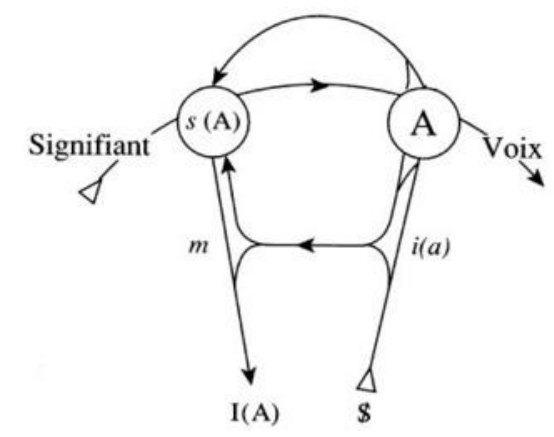

Como ilustrado no grafo, há um círculo que se instaura com a incidência do significante pelo vetor que de A - lugar do Outro/tesouro do significante - retorna ao s(A) - efeito de significação -, passando necessariamente pelo eixo imaginário, $\mathrm{i}(\mathrm{a})$ - $\mathrm{m}$. Esse momento do grafo, além de evidenciar teoricamente a proeminência do simbólico sobre o imaginário, registra uma perspectiva de grande importância teórica e clínica que considera os efeitos de significação e de sentido condicionados ao imaginário.

O significante faz uma marca. "Marca invisível que o sujeito recebe do significante" (Lacan, 1998, p. 822). No cerne dessa marca que Lacan visará o desenvolvimento freudiano: preenchendo essa marca - marca simbólica -, o traço unário, einziger Zug, surge e aliena o sujeito na identificação que forma o ideal de eu, Ich ideal. O eu ideal, ideal Ich, é uma imagem que se fixa a partir do ponto que o sujeito se identifica ao ideal do eu:

É essa imagem que se fixa, eu ideal, desde o ponto em que o sujeito se detém como ideal do eu. [...] Na captura que sofre de sua natureza imaginária, ele mascara sua duplicidade, qual seja, que a consciência com que ele garante a si mesmo uma existência incontestável [...] não the é dado de modo algum imanente, mas transcendente, uma vez que se apoia no traço unário do ideal do eu. (Lacan, 1998, p. 823)

Desse modo, desenvolve-se a perspectiva de que a imagem tem a propriedade de ser fixa, no cerne do imaginário, exatamente mediante a identificação possibilitada pelos efeitos de significação advindos da retroação da cadeia significante. Trata-se, portanto, da efetuação da identificação imaginária e de sua repetição. No Seminário XIX, ...ou pior, no âmbito de outro desenvolvimento teórico - referente ao domínio lógico do significante enquanto Um - Lacan retomará essa questão:

A marca como tal, o traço unário, aponta um suporte típico, isto é, imaginário, mas só não constitui um juízo de valor, como também tudo que eu disse, escrevi, inscrevi nos grafos, esquematizei num modelo óptico, na época, no qual o sujeito se reflete 
no traço unário, e no qual é somente a partir daí que ele se repete como eu ideal, tudo isso insiste justamente em que a identificação imaginária se efetua por uma marca simbólica. [...] Um porco, erguendo-se sobre as patas traseiras e bancando de por ereto, nem por isso deixa de ser o porco que era originalmente. Mas só ele pode imaginar que não nos lembramos disso. (Lacan, 2012, p. 161)

Importante observar aqui que, segundo Jacques-Alain Miller (1997, p. 576), é com o forjamento da categoria de significante-mestre que Lacan pode reagrupar conceitualmente ideal de eu e Nome-do-Pai.

\section{Fechamento da via imaginária, a solução fálica e o fantasma}

Posteriormente será incluso, na teorização da incidência do significante no imaginário e seus efeitos, a consideração acerca da tríade necessidade/demanda/desejo. Identificando o lugar do Outro, o tesouro do significante, com a Mãe, Lacan poderá situar no âmago da estrutura a cena edípica e o subsequente complexo de castração. O Pai é concebido como representante original da Lei, um Legislador que se perfila por sua impostura frente à falta de uma lei primordial que ordenaria a cadeia, haja vista que não há metalinguagem (Lacan, 1998, p. 827-828). A lei refreia o fantasma de onipotência do Outro na medida em que se evidencia a demanda, e o desejo possibilita a inversão da condição de sujeição do sujeito ao Outro. Havendo assim, a insurgência do desejo no campo do Outro, abrem-se as condições para que o sujeito se coordene à falta de modo diferente.

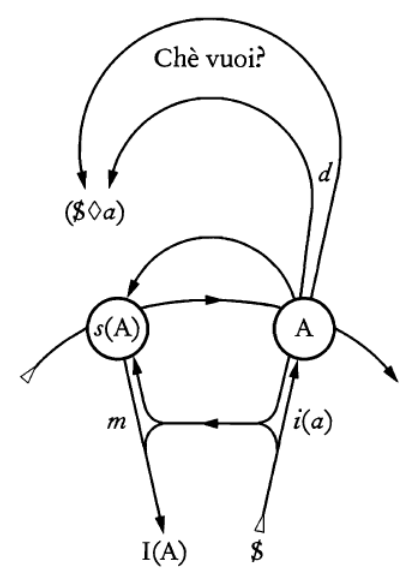

A clássica questão "Chè vuoi? - que quer você?"se formula. Esta questão é a que melhor "conduz ao caminho de seu próprio desejo", diz Lacan, "caso ele se ponha, graças à habilidade de um parceiro chamado psicanalista" (Lacan, 1998, p. 829), pois é antecipada pela insciência, ou ignorância, de onde o sujeito deseja. "O desejo do homem é o desejo do Outro", acrescenta Lacan, "é como Outro que ele deseja" (Lacan, 1998, p. 829). 
Essa condição que divide o sujeito está ligada intimamente à fenda, Spaltung, aberta pela incidência do significante e pela sua subordinação a ele. É a partir desse ponto de avanço do grafo que Lacan poderá localizar o cerne da experiência analítica. "Assim se fecha a via imaginária por onde na análise devo advir, lá onde s'tava [là ou s'était] o inconsciente" (Lacan, 1998, p. 831).

Enfim, Lacan tomará a imagem fálica como função imaginária da castração, resultante da equação do imaginário e do simbólico. O (- $\varphi$ ) estará contido no fantasma "sob uma forma oculta e reversível", remetendo-se à falta.

\section{O que não tem imagem}

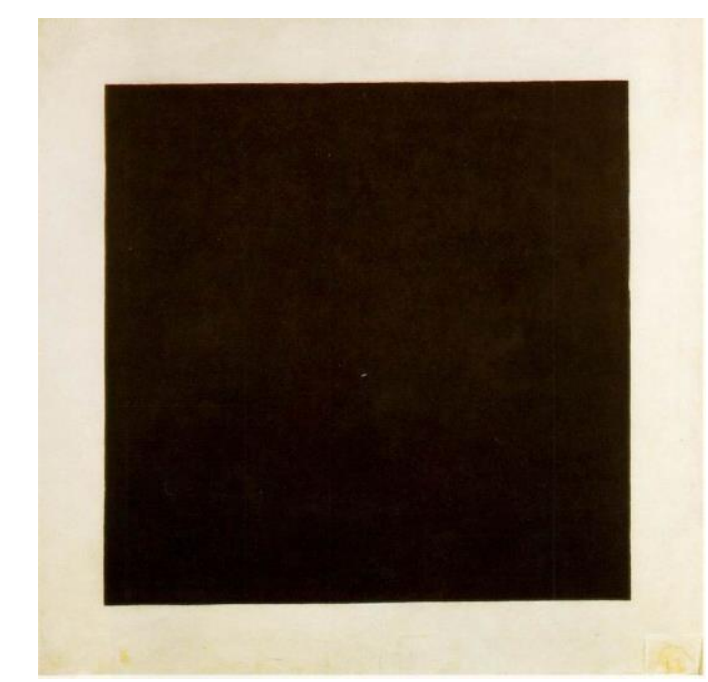

Quadro negro sobre fundo branco, óleo sobre tela, Kazemir Malevich, 1915

Como desenvolvi acima, as imagens, ou melhor, as imagens rainhas se localizam no âmbito de uma compreensão estrutural que se desenvolve a partir da proeminência do simbólico. Em dois escritos fundamentais, "Estádio do espelho" (Lacan, 1998) e "Subversão do sujeito" (Lacan, 1998), já se encontram situadas a proeminência dessas imagens. No entanto, como sinaliza Miller em "A imagem rainha" (Miller, 1997), concomitante à eleição dessas imagens, também é importantíssimo situar teoricamente o que está além da imagem sustentando a própria imagem: o objeto a. Partindo do paradigma escópico presente no Seminário 11 (Lacan, 2008), o objeto a vai adquirindo cada vez mais um estatuto lógico no âmbito do ensino de Jacques Lacan.

Em $A$ arte, a psicanálise, o século, Gerard Wajcman (2012) considera que a formulação do objeto a por Jacques Lacan acompanha uma característica muito própria à arte moderna: afastar-se do visível, da realidade, do sentido e do belo, em suma, do imaginário. Um movimento que, segundo o autor, inicia-se com o fim do "reino milenar da imagem simbólica", iniciada principalmente por Édouard Manet e Paul Cézanne. Wajcman encontra no abstracionismo moderno, de Kazemir Malevitch, a melhor expressão artística da falta de objeto. Segundo ele, Quadro negro sobre fundo 
branco é "a ausência do objeto encarnada", e também uma dobra, pois é "um objeto que opera uma presentificação da falta de objeto" (Wajcman, 2012, p. 71-72).

No objeto $a$, trata-se de uma elisão de estrutura, que só pode ser representada por um suplemento. Assim, como buraco, ele pode ser equivalente à moldura, à janela, oposto ao espelho. Não podemos captar o objeto $a$, especialmente no espelho. Lacan, que passou tanto tempo com o espelho, diz isso. Pois é a janela que constituímos nós mesmos, abrindo os olhos. (Miller, 1997, p. 587)

No tocante às identificações imaginárias e às suas imagens, tão cultivadas e patrocinadas na cultura contemporânea, tomamo-las pela perspectiva de que estejam vinculadas às soluções frente ao real enquanto impossível de suportar. Ou seja: é na clínica psicanalítica que as identificações imaginárias perdem seu estatuto de identidades normativas para, enfim, ganharem estatuto clínico.

\section{Referências bibliográficas}

Coelho dos Santos, T. \& Zucchi, M. A. (2007). Estrutura e gozo: os novos sintomas como solução na neurose e na psicose. In Freire, A. B. (Org.). Apostar no sintoma (pp. 61-83). Rio de Janeiro: Contracapa.

Freud, S. (2010). Introdução ao narcisismo. Introdução ao narcisismo: ensaios de metapsicologia e outros textos (1914-1916). São Paulo: Companhia das Letras.

Freud, S. (2010). Os instintos e seus destinos. Introdução ao narcisismo: ensaios de metapsicologia e outros textos (1914-1916). Op. cit.

Furman, M. (2014). Identificação. In Machado, O. \& Ribeiro, V. A. (Eds). Um real para o século XXI. Belo Horizonte: Scriptum.

Lacan, J. (1998). Posição do inconsciente. Escritos. Rio de Janeiro: Zahar.

Lacan, J. (1998). O estádio do espelho como formador da função do eu. Escritos. Op. cit.

Lacan, J. (1998). Subversão do sujeito e a dialética do desejo no inconsciente freudiano. Escritos. Op. cit.

Lacan, J. (1978). Seminaire II, Les écrits techniques de Freud. Paris: Seuil.

Lacan, J. (2008). O seminário, livro 11: os quatro conceitos fundamentais da psicanálise. Rio de Janeiro: Zahar.

Lacan, J. (2008). O seminário, livro 16: de um Outro ao outro. Rio de Janeiro: Zahar.

Lacan, J. (1992). O seminário, livro 17: o avesso da psicanálise. Rio de Janeiro: Zahar.

Lacan, J. (2011). O seminário, livro 19: ... ou pior. Rio de Janeiro: Zahar.

Miller, J.-A. (2006). La imagen del cuerpo en psicoanálisis. Introdución a la clínica lacaniana, conferencias en España. Madrid: ELP. 
Miller, J.-A. (1997). A imagem rainha. Lacan elucidado. Rio de Janeiro: Zahar.

Miller, J.-A. (2005). A pulsão escópica. Silet-Paradoxos da pulsão de Freud a Lacan. Rio de Janeiro: Zahar.

Miller, J.-A. (2005). O real no século XXI. Um real para o século XXI. Belo Horizonte: Scriptum.

Miller, J.-A. (2009). Acto y inconsciente. Conferencias porteñas. BsAs: Paidós.

Wajcman, G. (2012). A arte, a psicanálise, o século. Lacan, o escrito, a imagem. Belo Horizonte: Autêntica.

Citacão/Citation: Kunst, M. H. (mai. a out. 2015). Considerações acerca da noção de imagem em psicanálise. Revista aSEPHallus de Orientação Lacaniana, 10(20), 50-60. Disponível em www.isepol.com/asephallus. doi: 10.17852/1809-709x.2019v10n20p50-60

Editor do artigo: Tania Coelho dos Santos.

Recebido/Received: 25/08/2015 / 08/25/2015.

Aceito/Accepted: 08/09/2015 / 09/08/2015.

Copyright: (c) 2013 Associação Núcleo Sephora de Pesquisa sobre o moderno e o contemporâneo. Este é um artigo de livre acesso, que permite uso irrestrito, distribuição e reprodução em qualquer meio, desde que o autor e a fonte sejam citados/This is an open-access article, which permites unrestricted use, distribution, and reproduction in any medium, provided the author and source are credited. 